\title{
The Insider: its effect on the public
}

"The Insider" recounts the chain of events that pitted an ordinary man against the tobacco industry and dragged two people into the fight of their lives over seeking out the truth; one a scientist and one a journalist. The movie shows the lengths big tobacco will go to protect a multi billion dollar a year addiction, including using its enormous power to threaten the news media. The movie blends the roles of numerous individuals who were involved in unveiling the tobacco industry's deceit and disregard for public health and safety over decades.

Since the movie premiered in October 1999 I have received over 5963 unsolicited emails addressed to my web site as well as letters recounting individuals' reactions to the movie. I maintain a $\log$ of these responses. Of these, some 2654 have indicated that after viewing the movie, being exposed to the behaviour of the tobacco industry, gleaning a better understanding of how a cigarette is designed, and hearing about the manipulation of nicotine and the use of additives, many have told me that they have quit smoking.

I was quite surprised as to the effect the movie was having on a broad base of individuals, from all over the world. I can concur with the observations of Dixon and colleagues ${ }^{1}$ and have taken my work one step further by making another movie - a one hour educational video for students and tobacco control activists called Secrets Through the Smoke (single copies, free of charge, may be ordered through http://www.cdc.gov/tobacco/ssmoke.htm).

The Insider, in addition to depicting tobacco industry executives accurately as merchants of death and greed who will do anything to save their addictive killing product, also dramatically shows how one person can make a difference by standing up and being counted The power of the press and truth can win out. Movies have the capacity to make a difference; especially those that convey positive and realistic messages regarding tobacco use. Based on my experience and reading the research of the authors, I strongly support efforts that continue to demystify the labyrinth of misinformation the tobacco industry has fostered for so many decades.

Smoke-Free Kids, Inc

JEFF WIGAND

Charleston

South Carolina

USA

7SW700@aol.com

I acknowledge the assistance of J Kartak (webmistress) and $M$ Havard (CDC) in tabulating the emails and letters.

1 Dixon HG, Hill DJ, Borland R, et al. Public reaction to the portrayal of the tobacco industry in the film The Insider. Tobacco Control 2001;10:285-91.

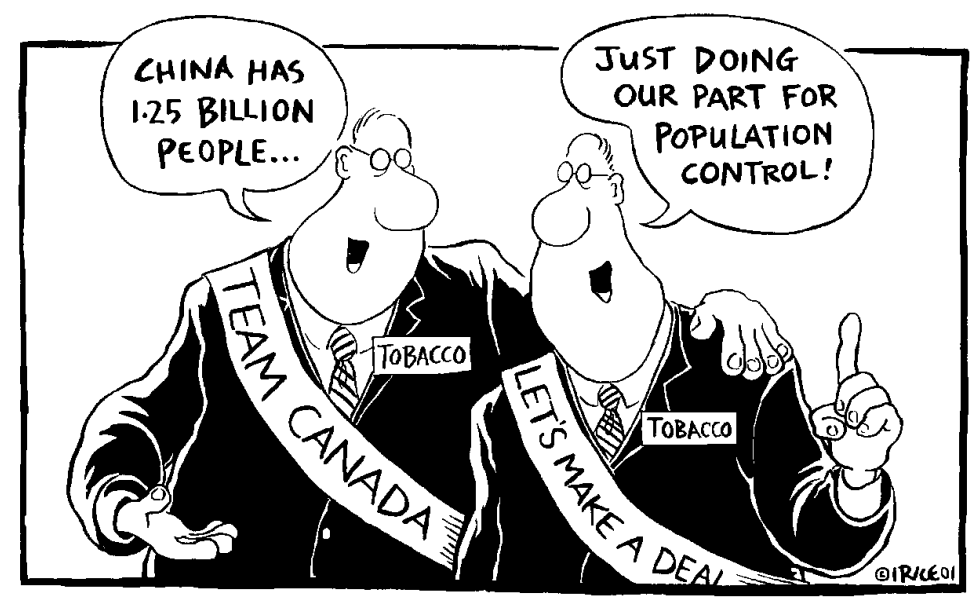

IN DEFENSE OF TOBACCO INTERESTS PARTICIPATING IN THE TEAM CANADA TRADE MISSION

(C) Ingrid Rice. 